$$
\frac{r\left(\mathrm{H}^{\prime}-\mathrm{H}\right) 772}{r\left(\mathrm{t}^{\prime}-t\right) 8.723}=\frac{r .305\left(\mathrm{t}^{\prime}-t\right) 772}{r\left(\mathrm{t}^{\prime}-t\right) 8.723}=26.9 \text {, or that }
$$

only $\frac{1}{2} \gamma^{\text {th }}$ part of the total heat can possibly be realized theoretically.

This article is only preliminary; but the opinion of the writer at present is that the latent heat performs the internal work, while the sensible heat only is available for external work. If this is correct, then that vapor whose latent heat is the smallest, other things equal, would be the best agent for converting heat into work.

\title{
THE ICE-GORGE IN THE SCHUYLKILL ABOVE FAIRMOUNT.
}

By JohN W. Murphy.

A paper read before the Franklin Institute.

The ice-gorge in the Schuylkill, at 'Turtle Rock, extending backwards up the stream some seven miles in distance, has attracted a good deal of attention.

The fear of the effect of the sudden disgorge of this enormous mass of ice has given grave apprehension to the oitizens of Philadelphia.

The Fairmount Dam is in danger. If it gives way, damage and destruction follows. Market street, Chestnut street and the partially completed South street bridges will be swept out of existence.

There is nothing, therefore, that engineering skill can or has devised that can withstand this terrific gorge if once in motion.

Think for a moment of a field of ice some miles long, seven hundred feet wide and twenty feet deep, moved by a freshet such as would send it crashing its way against every obstruction that impeded its progress!

Now the purpose of this paper is to show that this gorge of ice is in fact the protection to all structures below it.

Ice is gorged under two conditions of the stream; the first condition is when the stream is rising, the other is when the water falls. Persons who are accustomed to look upon the breaking up of ice in the river, and seeing masses of ice moved by a freshet, rarely comprehend the difference between an ice-gorge that may last for a moment, for an hour or for two hours, and then break away by force of a continually rising current, and a gorge of ice that has been stranded upon the bottom of a river, where the freshet runs away from it, and leaves it high and dry. 
In the latter case, the first portion of the ice-floe is stopped, and jammed against the shores. The water running from underneath it allows it to sink to the bottom. The ice following after accumulates behind, piling in upon the stranded obstruction in front. The subsidiary water fails in strength to move forward the obstruction and only gives opportunity to make the barrier stronger.

An observation of the ice-gorge above the dam at Fairmount shows us that each cake of ice has been set down to the bottom of the river edgewise. As evidence of it, any one who will glance at the surface of it will see that every stick of wood, debris and logs and all light floating material stand upright, as though an engineering party had been driving stakes to make a topographical survey of the territory.

A gorge of ice is always an evidence of a falling stream, in fact it may almost be said a season of drought (low water).

Consequently, before a gorge can be raised, and moved to be deatructive to structures below it, there must be a volume of water poured into the stream at least three times greater than the initial freshet that caused the gorge.

If ice weighs 58 pounds and water $62 \frac{1}{2}$ pounds to the cubic foot, it will be elear that the difference in flotation will be as 58 is to $62 \frac{1}{2}$; in other words, one-sixth in round numbers will be out of water and five-six ths will be submerged.

Now, where a freshet occurs and carries with it a mass of ice fivesixths of which is under water and one-sixth above, whatever be the thickness of the ice, it carries with it elements of great destruction; because the specific gravity of ice is so near to that of water, that when it has great thickness and relocity it acts against any obstruetion like a projectile.

An ice-gorge and an ice freshet are widely different, for in the case of the ice freshet the horizontal mass, whatever may be its thickness, is raised from its normal condition and moved forward by the flood.

Referring, then, to our thought, that five-sixths of the ice is below the surface of the water, and, if it be in a condition of flotation, it will require a freshet of 16 feet, measured on the dam at Fairmount, to move the garge bodily.

I therefore conclude that no danger may be apprehended below any gorge similarly situated as the one above the dam at Fairmount. 